\title{
Blackfish Optimization Algorithm for Solving Reactive Power Problem
}

\author{
K Lenin*, B Ravindhranath Reddy, M Surya Kalavathi \\ Department of Electrical and Electronics Engineering, JNTU, Hyderabad 500 085, India \\ *Corresponding author, e-mail:gklenin@gmail.com
}

\begin{abstract}
In this paper Blackfish Algorithm (BA) has been utilized to solve the optimal reactive power problem. BA is inspired from bubble net hunting strategy of the black fish. In this algorithm roulette wheel selection method has been used to improve the convergence rate. The proposed BA has been tested in standard IEEE 30 bus test system and simulation results show clearly about the better performance of the proposed algorithm in reducing the real power loss with control variables within the limits.
\end{abstract}

Keywords: Blackfish Algorithm, bubble net hunting strategy, optimal reactive power, transmission loss

\section{Introduction}

To till date various methodologies has been applied to solve the Optimal Reactive Power problem. The key aspect of solving Reactive Power problem is to reduce the real power loss. Previously many types of mathematical methodologies like linear programming, gradient method (Alsac et al., 1973; Lee et al., 1985; Monticelli et al., 1987; Deeb et al., 1990; Hobson, 1980; Lee et al., 1993; Mangoli et al., 1993; Canizares et al., 1996) [1-8] has been utilized to solve the reactive power problem, but they lack in handling the constraints to reach a global optimization solution. In the next level various types of evolutionary algorithms (Berizzi et al., 2012; Roy et al., 2012; Hu et al., 2010; Eleftherios et al., 2010) [9-12] has been applied to solve the reactive power problem. This paper propose Blackfish algorithm (BA) for solving reactive power problem. BA is inspired by the bubble-net hunting strategy of Black fish (Seyedali Mirjalili et al., 2016) [13]. BA utilizes roulette wheel selection method to improve the speed of convergence. Proposed BA algorithm has been evaluated on standard IEEE 30 bus test system. The simulation results show that the proposed approach outperforms all the entitled reported algorithms in minimization of real power loss.

\section{Objective Function}

\subsection{Active Power Loss}

The objective of the reactive power dispatch problem is to minimize the active power loss and can be defined in equations as follows:

$$
\mathrm{F}=P_{L}=\sum_{\mathrm{k} \in \mathrm{Nbr}} \mathrm{g}_{\mathrm{k}}\left(\mathrm{V}_{\mathrm{i}}^{2}+\mathrm{V}_{\mathrm{j}}^{2}-2 \mathrm{~V}_{\mathrm{i}} \mathrm{V}_{\mathrm{j}} \cos \theta_{\mathrm{ij}}\right)
$$

Where F- objective function, $P_{L}$ - power loss, $g_{k}$ - conductance of branch, $V_{i}$ and $V_{j}$ are voltages at buses $\mathrm{i}, \mathrm{j}$, Nbr- total number of transmission lines in power systems.

\subsection{Voltage Profile Improvement}

To minimize the voltage deviation in $\mathrm{PQ}$ buses, the objective function (F) can be written as:

$$
\mathrm{F}=P_{L}+\omega_{\mathrm{v}} \times \mathrm{VD}
$$

Where VD - voltage deviation, $\omega_{\mathrm{v}}$ - is a weighting factor of voltage deviation.

And the Voltage deviation given by: 


$$
\mathrm{VD}=\sum_{\mathrm{i}=1}^{\mathrm{Npq}}\left|\mathrm{V}_{\mathrm{i}}-1\right|
$$

Where Npq- number of load buses

\subsection{Equality Constraint} follows:

The equality constraint of the problem is indicated by the power balance equation as

$$
\mathrm{P}_{\mathrm{G}}=\mathrm{P}_{\mathrm{D}}+\mathrm{P}_{\mathrm{L}}
$$

Where $\mathrm{P}_{\mathrm{G}}$ - total power generation, $\mathrm{P}_{\mathrm{D}}$ - total power demand.

\subsection{Inequality Constraints}

The inequality constraint implies the limits on components in the power system in addition to the limits created to make sure system security. Upper and lower bounds on the active power of slack bus $\left(P_{g}\right)$, and reactive power of generators $\left(Q_{g}\right)$ are written as follows:

$$
\begin{aligned}
& \mathrm{P}_{\text {gslack }}^{\min } \leq \mathrm{P}_{\text {gslack }} \leq \mathrm{P}_{\text {gslack }}^{\max } \\
& \mathrm{Q}_{\mathrm{gi}}^{\min } \leq \mathrm{Q}_{\mathrm{gi}} \leq \mathrm{Q}_{\mathrm{gi}}^{\max }, \mathrm{i} \in \mathrm{N}_{\mathrm{g}}
\end{aligned}
$$

Upper and lower bounds on the bus voltage magnitudes $\left(\mathrm{V}_{\mathrm{i}}\right)$ is given by:

$$
V_{i}^{\min } \leq V_{i} \leq V_{i}^{\max }, i \in N
$$

Upper and lower bounds on the transformers tap ratios $\left(\mathrm{T}_{\mathrm{i}}\right)$ is given by:

$$
\mathrm{T}_{\mathrm{i}}^{\min } \leq \mathrm{T}_{\mathrm{i}} \leq \mathrm{T}_{\mathrm{i}}^{\max }, \mathrm{i} \in \mathrm{N}_{\mathrm{T}}
$$

Upper and lower bounds on the compensators $\left(Q_{c}\right)$ is given by:

$$
\mathrm{Q}_{\mathrm{c}}^{\min } \leq \mathrm{Q}_{\mathrm{c}} \leq \mathrm{Q}_{\mathrm{C}}^{\max }, \mathrm{i} \in \mathrm{N}_{\mathrm{C}}
$$

Where $\mathrm{N}$ is the total number of buses, $\mathrm{N}_{\mathrm{g}}$ is the total number of generators, $\mathrm{N}_{\mathrm{T}}$ is the total number of Transformers, $\mathrm{N}_{\mathrm{c}}$ is the total number of shunt reactive compensators.

\section{Blackfish Algorithm (BA)}

It inspired from the bubble-net hunting strategy of black fish. Algorithm describes the special hunting behaviour of Black fish, and bubbles which causes the creation of '9-shaped path' while encircling prey during hunting. Black fish went down in water roughly 10-16 meters and then it start to produce bubbles in a spiral shape encircles prey and then through the bubbles and it moves towards upward of the surface. Mathematic model of BA is given as follows [13]:

Encompassing prey equation

Black fish enfolds the prey then appraises its position towards the optimum solution over the sequence of swelling number of iteration from start to a maximum number of iteration [13].

$$
\begin{aligned}
& \vec{E}=|F \cdot \vec{Y} *(t)-Y(t)| \\
& \vec{Y}(t+1)=\vec{Y} *(t)-\vec{B} \cdot \vec{E}
\end{aligned}
$$

Where $\vec{B}, \vec{E}$ are coefficient vectors, $\mathrm{t}$ is a present iteration, $\vec{y} *(t)$ is position vector of the optimum solution and $Y(t)$ is position vector.

Coefficient vectors $\vec{B}, \vec{E}$ are computed as follows: 


$$
\begin{aligned}
& \vec{B}=2 \vec{g} * \text { rand }-\vec{g} \\
& \vec{F}=2 * \text { rand }
\end{aligned}
$$

Where $\vec{g}$ is a variable linearly decrease from 2 to 0 over the sequence of iteration and rand is a arbitrary number $[0,1]$.

Bubble-net deeds of Black fish are modelled by following methods [13]:

Dwindling enclosing mechanism

This process is engaged by reducing linearly the value of ' $g$ 'from 2 to 0 . Arbitrary value of vector $\vec{B}$ is range between $[-1,1]$.

Spiral modernizing position

Scientific spiral equation for position modernizing between Blackfish and prey was helix-shaped movement $\&$ is given as follows [13]:

$$
\vec{Y}(t+1)=\vec{E}^{*} e^{b t *} \cos (2 \pi l)+\vec{Y} *(t)
$$

Where $l$ is an arbitrary number $[-1,1]$, b is constant defines the logarithmic shape, $\vec{E}^{\prime}=$ $|\vec{Y} *(t)-Y(t)|$ expresses the distance between $\mathrm{i}^{\text {th }}$ Black fish to the prey mean the finest solution so far.

50-50\% probability of Black fish will either follow the dwindling enclosing path or logarithmic path during optimization.

Arithmetically it modelled as follows:

$$
\vec{Y}(t+1)=\left\{\begin{array}{c}
\vec{Y} * \vec{B} \vec{E} \quad \text { if } p<0.50 \\
\vec{E}^{\prime} e^{b t *} \cos (2 \pi l)+\vec{Y} *(t) \text { if } p \geq 0.50
\end{array}\right.
$$

Where $p$ is an arbitrary number $[0,1]$.

Exploration for prey

The vector $\vec{B}$ can be used for exploration to search for prey; vector $\vec{B}$ also takes the values greater than one or less than -1. Exploration follows two conditions,

$$
\begin{aligned}
& \vec{E}=\left|\vec{F} \cdot \overrightarrow{Y_{\text {random }}}-\vec{Y}\right| \\
& \vec{Y}(t+1)=\overrightarrow{Y_{\text {random }}}-\vec{B} \cdot \vec{E}
\end{aligned}
$$

Following two conditions have been followed in algorithm

$|\vec{B}|>1$ Imposes exploration on BA algorithm to find out global optimum.

$|\vec{B}|<1$ To update the position of present search agent

\section{Simulation Results}

Validity of Black fish algorithm has been verified by testing in IEEE 30-bus, 41 branch system and it has 6 generator-bus voltage magnitudes, 4 transformer-tap settings, and 2 bus shunt reactive compensators. Bus 1 is taken as slack bus and 2, 5, 8, 11 and 13 are considered as PV generator buses and others are $P Q$ load buses. Control variables limits are given in Table 1. 
Table 1. Primary Variable Limits (Pu)

\begin{tabular}{cccc}
\hline Variables & Min. & Max. & category \\
\hline Generator Bus & 0.9 & 1.1 & Continuous \\
Load Bus & 0.95 & 1.05 & Continuous \\
Transformer-Tap & 0.90 & 1.10 & Discrete \\
Shunt Reactive & - & 0.30 & Discrete \\
Compensator & 0.10 & & \\
\hline
\end{tabular}

In Table 2 the power limits of generators buses are listed.

Table 2. Generators Power Limits

\begin{tabular}{ccccc}
\hline Bus & Pg & Pgmin & Pgmax & Qgmin \\
\hline 1 & 96.00 & 49 & 200 & -19 \\
2 & 79.00 & 18 & 79 & -19 \\
5 & 49.00 & 14 & 49 & -11 \\
8 & 21.00 & 11 & 31 & -14 \\
11 & 21.00 & 11 & 28 & -12 \\
13 & 21.00 & 11 & 39 & -14 \\
\hline
\end{tabular}

Table 3 shows the proposed BA approach successfully kept the control variables within limits. Table 4 list out the overall comparison of the results of optimal solution obtained by various methods.

Table 3. After optimization values of control variables

\begin{tabular}{ll}
\hline Control Variables & BA \\
\hline V1 & 1.0517 \\
V2 & 1.0482 \\
V5 & 1.0279 \\
V8 & 1.0399 \\
V11 & 1.0798 \\
V13 & 1.0527 \\
T4,12 & 0.00 \\
T6,9 & 0.01 \\
T6,10 & 0.90 \\
T28,27 & 0.91 \\
Q10 & 0.10 \\
Q24 & 0.10 \\
Real power loss & 4.2879 \\
Voltage deviation & 0.9080 \\
\hline
\end{tabular}

Table 4. Comparison of results

\begin{tabular}{cc}
\hline Techniques & Real power loss (MW) \\
\hline SGA(Wu et al., 1998) & 4.98 \\
PSO(Zhao et al., 2005) & 4.9262 \\
LP(Mahadevan et al., 2010) & 5.988 \\
EP(Mahadevan et al., 2010) & 4.963 \\
CGA(Mahadevan et al., 2010) & 4.980 \\
AGA(Mahadevan et al., 2010) & 4.926 \\
CLPSO(Mahadevan et al., 2010) & 4.7208 \\
HSA (Khazali et al., 2011) & 4.7624 \\
BB-BC (Sakthivel et al., 2013) & 4.690 \\
BA & 4.2879 \\
\hline
\end{tabular}

\section{Conclusion}

In this paper, Blackfish algorithm has been effectively applied to solve Optimal Reactive Power Dispatch problem. The proposed BA algorithm has been tested in the standard IEEE 30 bus system. Simulation results show the heftiness of projected Blackfish algorithm in declining the real power loss. The control variables obtained after the optimization by BA are well within the limits. 


\section{References}

[1] Alsac O, B Scott. "Optimal load flow with steady state security". IEEE Transaction. 1973; PAS: 745751.

[2] Lee KY, Paru YM, Oritz JL. "A united approach to optimal real and reactive power dispatch". IEEE Transactions on power Apparatus and systems. 1985; PAS-104 : 1147-1153.

[3] Monticelli A, MVF Pereira, S Granville. "Security constrained optimal power flow with post contingency corrective rescheduling". IEEE Transactions on Power Systems: PWRS-2. 1987; 1: 175182.

[4] Deeb N, Shahidehpur SM. "Linear reactive power optimization in a large power network using the decomposition approach". IEEE Transactions on power system. 1990; 5(2): 428-435

[5] Hobson E. "Network consrained reactive power control using linear programming". IEEE Transactions on power systems. 1980; PAS -99(4): 868-877.

[6] Lee KY, YM Park, JL Oritz. "Fuel -cost optimization for both real and reactive power dispatches". IEE Proc. 1993; 131C(3): 85-93.

[7] Mangoli MK, KY Lee. "Optimal real and reactive power control using linear programming". Electr. Power Syst. Res. 1993; 26: 1-10.

[8] Canizares CA, ACZ de Souza, VH Quintana. "Comparison of performance indices for detection of proximity to voltage collapse". 1996; 11(3): 1441-1450.

[9] Berizzi C Bovo, M Merlo, M Delfanti. "A ga approach to compare orpf objective functions including secondary voltage regulation". Electric Power Systems Research. 2012; 84(1): 187 - 194.

[10] RoyP, S Ghoshal, S Thakur. "Optimal var control for improvements in voltage profiles and for real power loss minimization using biogeography based optimization". International Journal of Electrical Power and Energy Systems. 2012; 43(1): 830 - 838.

[11] Hu Z, X Wang, G Taylor. "Stochastic optimal reactive power dispatch: Formulation and solution method". International Journal of Electrical Power and Energy Systems. 2010; 32(6): 615 - 621.

[12] Eleftherios I Amoiralis, Pavlos S Georgilakis, Marina A Tsili, Antonios G Kladas. "Ant Colony Optimisation solution to distribution transformer planning problem". InternationI Journal of Advanced Intelligence Paradigms. 2010; 2(4): 316 - 335.

[13] Seyedali Mirjalili, Andrew Lewis. "The whale optimization algorithm". Advances in Engineering Software. 2016; 95: 51-67.

[14] Wu QH, YJ Cao, JY Wen. "Optimal reactive power dispatch using an adaptive genetic algorithm". Int. J. Elect. Power Energy Syst. 1998; 20: 563-569.

[15] Zhao B, CX Guo, YJ CAO. "Multiagent-based particle swarm optimization approach for optimal reactive power dispatch". IEEE Trans. Power Syst. 2005; 20(2): 1070-1078.

[16] Mahadevan K, Kannan PS. "Comprehensive Learning Particle Swarm Optimization for Reactive Power Dispatch". Applied Soft Computing. 2010; 10(2): 641-52.

[17] Khazali AH, M Kalantar. "Optimal Reactive Power Dispatch based on Harmony Search Algorithm". Electrical Power and Energy Systems. 2011; 33(3): 684-692.

[18] Sakthivel S, M Gayathri, V Manimozhi. "A Nature Inspired Optimization Algorithm for Reactive Power Control in a Power System". International Journal of Recent Technology and Engineering. 2013; 2(1): 29-33. 